\title{
Projeto de edifícios altos: reflexões $\in$ considerações para o projeto estrutural
}

\author{
AUGUSTO G. PEDREIRA DE FREITAS - CONSELHEIRO \\ ABECE
}

\author{
MAURÍCIO MARTINS PIRES \\ Pedreira Engenharia
}

\section{RESUMO}

OS AUTORES CONSIDERAM NO TEXTO SE OS PARÂMETROS NORMATIVOS DA ABNT NBR 6118 E 6123 ESTÃO ALINHADOS COM O PROJETO DE ESTRUTURAS DE EDIFÍ́CIOS ALTOS E FAZEM SUGESTÕES PARA A ANÁLISE DO
CONFORTO DOS USUÁRIOS DESSAS EDIFICAÇÕES, COM RESPEITO À ESCOLHA DO SISTEMA ESTRUTURAL E À NECESSIDADE DE CONTRATAÇÃO DE ENSAIO DE TÚNEL DE VENTO.

Palavras-chave: projeto de estruturas, edifícios altos, normalização, sistema estrutural, túnel de vento.

\section{INTRODUÇÃO}

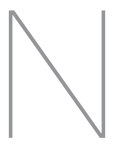

ovos desafios estão cada vez mais presentes na vida de um projetista estrutural.

A evolução dos modelos e dos softwares permite uma análise cada vez mais precisa da estrutura e isto vem sendo muito bem aproveitado pelos arquitetos.

É necessário, no entanto, avaliar o tamanho e as necessidades de conhecimento para cada desafio. Se o projetista se apoiar "cegamente" em normas e softwares, os resultados obtidos podem comprometer o desempenho esperado para a estrutura.

O projeto de edifícios altos exige um constante questionamento sobre os conceitos consolidados e os modelos de cada estrutura. É importante entender se esses refletirão, de uma forma aceitável, a estrutura em uso (sobretudo no estado limite de utilização, na análise do conforto do usuário).

\section{ALINHAMENTO DA NORMALIZAÇÃO EXISTENTE COM O PROJETO ESTRUTURAL DE PRÉDIOS ALTOS}

No desenvolvimento dos projetos estruturais de prédios altos, constantemente nos questionamos e refletimos sobre os conceitos e premissas que são consolidados para as estruturas usuais.

Acreditamos que a "norma deve refletir o estado da arte da engenharia no momento" (conforme orientação da ABNT). Esta frase é importante para entendermos que as normas precisam de uma evolução constante e que é extremamente perigoso usar normas ultrapassadas para estruturas atuais.

Da mesma forma, estruturas inovadoras podem não estar contempladas pelas normas atuais e podem ser necessárias análises complementares, que deverão fazer parte de revisões futuras dessas normas.

\section{I NBR 6II8}

A consulta à nossa "norma mãe" nos remeteu a uma análise que foi feita na época em que tivemos grandes mudanças, mais precisamente em 1980 e 2003.

Nesta época, lembro de questionamentos no sentido de que as novas exigências normativas indicariam que os prédios projetados pela norma anterior (com bom desempenho em uso) não atenderiam a determinados conceitos da nova norma.

No trabalho de conclusão de curso Concepção estrutural e dimensionamento de pilares de um edifício de concreto armado pelas normas NB1 (1960) e NBR 6118 (2003) - Uma visão de segurança (Peviani, G., 2014), concluiu-se que a norma NB1/60 era adequada ao tipo de edificações, materiais (mais especificamente o concreto) e vedações utilizados na década de 60, deixando de ser adequada às edificações 
da década de 80/90. Nos anos 2000, passamos a ter edifícios que, se projetados pela norma de 1960, correriam um sério risco de colapso.

As estruturas foram ficando mais esbeltas, com vedações desassociadas e uso de concreto de elevada resistência. O detalhamento dessas estruturas exigiu novos modelos, novos parâmetros normativos, refletindo o estado da arte deste novo momento.

A reflexão necessária é se essas estruturas muito altas e/ou esbeltas, estariam alinhadas com os parâmetros normativos da NBR 6118 atual? Não temos a resposta, mas uma análise sobre um parâmetro extremamente importante para a avaliação da estabilidade global nos faz, no mínimo, pensar a respeito.

Temos notado que nos prédios muito altos, a estrutura necessária para garantir um conforto mínimo ao usuário, quanto à aceleração e deformações devido ao vento, conduz a um $\gamma_{z}$ abaixo de 1,10. Um $\gamma_{z}$ de até 1,25, que pode ser considerado um valor comum para prédios usuais, não

Tabela 1 - Velocidades de vento para Balneário Camboriú obtidas em isopletas, laboratórios de túnel de vento e profissionais da área

\begin{tabular}{ccc} 
Fonte & \multicolumn{2}{c}{$\mathrm{V}_{0}$} \\
\hline A & $70 \mathrm{~m} / \mathrm{s}$ & $252 \mathrm{~km} / \mathrm{h}$ \\
B & $43 \mathrm{~m} / \mathrm{s}$ & $155 \mathrm{~km} / \mathrm{h}$ \\
\hline C & $42,8 \mathrm{~m} / \mathrm{s}$ & $154 \mathrm{~km} / \mathrm{h}$ \\
D & $42 \mathrm{~m} / \mathrm{s}$ & $151 \mathrm{~km} / \mathrm{h}$ \\
\hline E & $39 \mathrm{~m} / \mathrm{s}$ & $140 \mathrm{~km} / \mathrm{h}$ \\
F & $36,8 \mathrm{~m} / \mathrm{s}$ & $132 \mathrm{~km} / \mathrm{h}$ \\
G & $35,2 \mathrm{~m} / \mathrm{s}$ & $127 \mathrm{~km} / \mathrm{h}$ \\
H & $34,9 \mathrm{~m} / \mathrm{s}$ & $126 \mathrm{~km} / \mathrm{h}$ \\
I & $33,2 \mathrm{~m} / \mathrm{s}$ & $120 \mathrm{~km} / \mathrm{h}$ \\
J & $31,9 \mathrm{~m} / \mathrm{s}$ & $115 \mathrm{~km} / \mathrm{h}$ \\
\hline
\end{tabular}

seria uma boa referência para o projeto de edifícios muito altos, uma vez que o ELS passa a preponderar sobre o ELU de forma significativa.

\subsection{NBR 6I23}

A norma de vento é de 1988, estando em revisão desde 2016, ainda sem conclusão prevista.

Será que esta norma reflete o estado da arte de hoje? Acreditamos que não. Existe uma série de pontos que precisam ser revisados.

\subsection{Vo}

Um primeiro ponto é a velocidade básica do vento de referência.

As isopletas atuais foram desenvolvidas com uma base de dados restrita.
Hoje, temos uma base de dados (mesmo que vários deles com problemas) bem maior, além de alterações climáticas que devem ser avaliadas.

Com relação ao Vo, participamos de uma investigação para a cidade de Balneário Camboriú, que, a partir da consulta a diversos profissionais de renome (Tabela 1), obteve uma variação de valores muito grande entre as isopletas disponíveis.

Em 2019, foi concluída a tese de doutorado do eng. Matthew B.Vallis, que propôs um novo mapa de isopletas, com base numa análise muito ampla de todos os dados disponíveis no Brasil, com correções de distorções (Figura 1). Não temos expertise para avaliar, mas nos parece coerente e embasada, o que a credencia a ser discutida na revisão da norma.

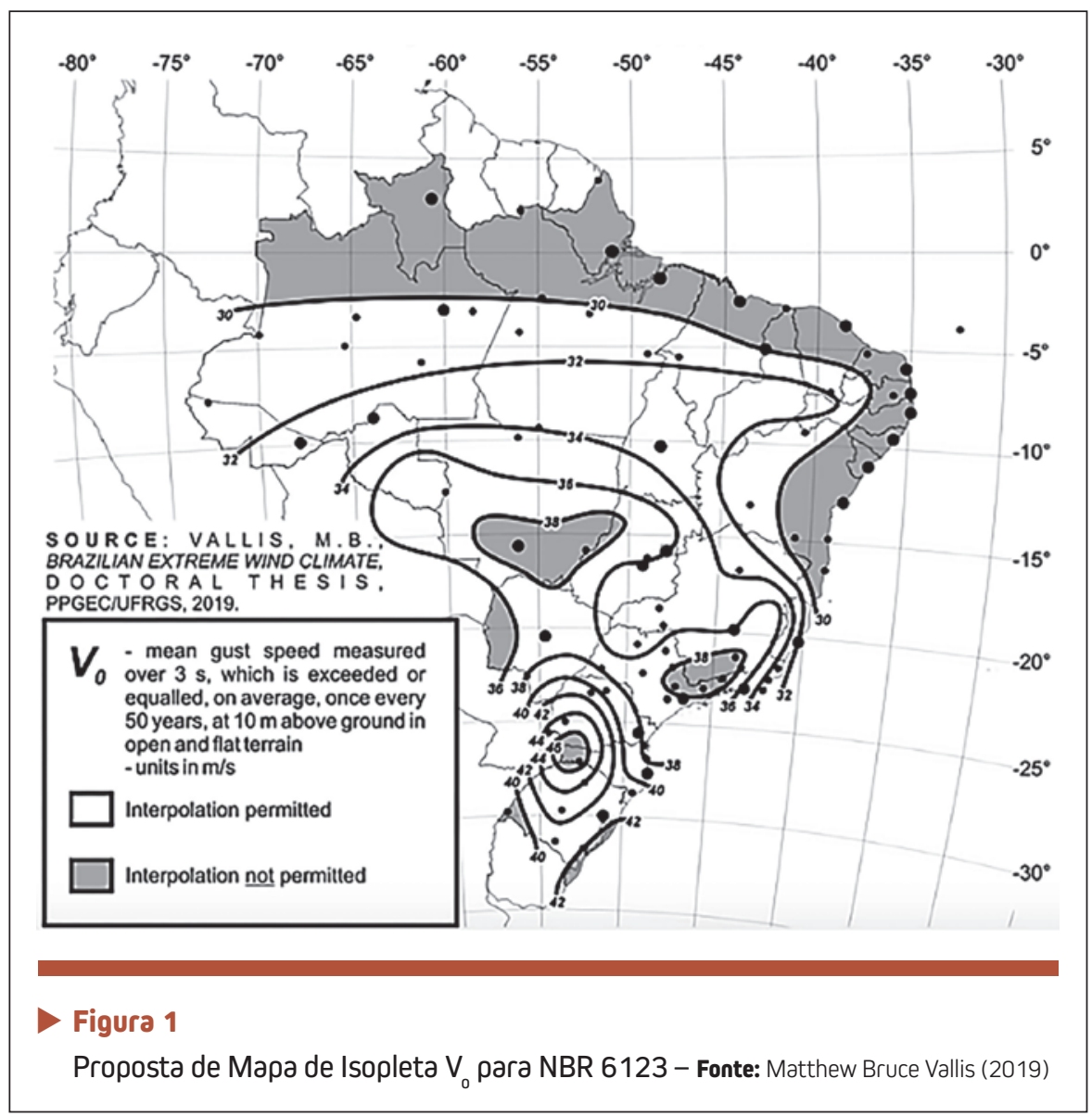




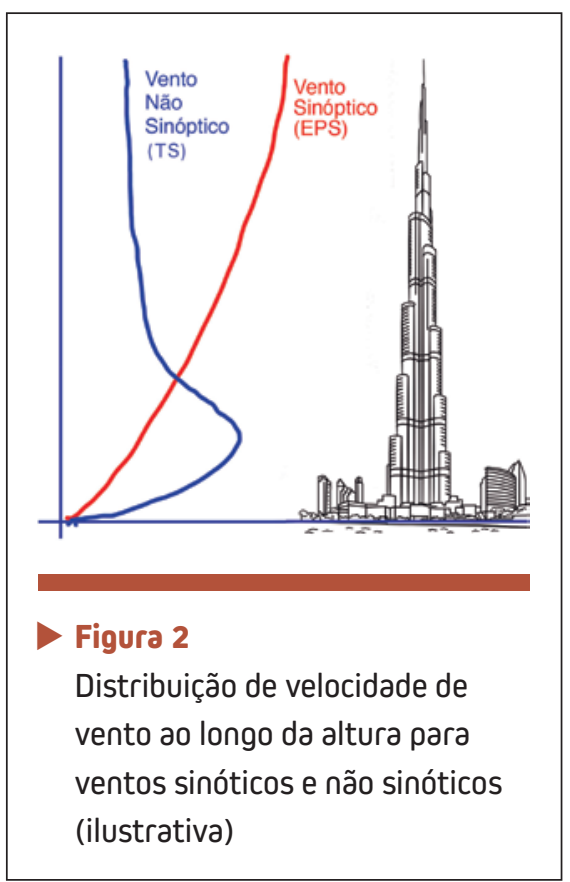

Outro ponto a ser avaliado é se devemos tratar os fenômenos de ventos sinóticos (EPS, extended pressure systems) e não sinóticos (TS, tornados e downbursts) com isopletas diferentes.

O trabalho do prof. Jorge D. Riera (Sobre a definição do vento para projeto estrutural na ABNT 6123 e outras normas sul-americanas) mostra que a variação da velocidade ao longo da altura tem uma distribuição bem diferente para os dois casos, com impactos bem diferentes para edificações baixas e muito altas.

Tabela 2 - Taxas de amortecimento

\begin{tabular}{|c|c|}
\hline Material & $\begin{array}{c}\text { Taxa de } \\
\text { amortecimento } \\
\text { para } 1 \text { a } 10 \text { anos } \\
\text { de periodo de } \\
\text { recorrência } \\
\text { do vento }\end{array}$ \\
\hline Concreto & $2 \%$ \\
\hline Aço & $1 \%$ \\
\hline
\end{tabular}

\section{२.ट.२ CONFORTO}

Outro ponto que merece discussão e evolução na norma NBR 6123 é o conforto.

Existem diversos estudos a respeito deste assunto e entendemos que é um ponto a ser avaliado pela comunidade técnica.

No mundo inteiro, vemos esforços no entendimento de como os movimentos das estruturas realmente interferem na sensação de conforto humano, buscando-se viabilizar estruturas altas, sem comprometer o desempenho. Precisamos estar alinhados com a comunidade internacional para não ficarmos para trás do ponto de vista do desenvolvimento da engenharia estrutural.

Nossas reflexões e análise das propostas, remetem às seguintes sugestões ${ }^{1}$ de análise de conforto para ser avaliada pela comissão de revisão:

a) Critérios para definição da Velocidade do Vento para efeito de análise dos parâmetros de Conforto:

- Entendemos que, para a análise de conforto, a velocidade básica do vento (Vo) deve ser usada com período de recorrência de 10 anos, como está na norma, permitindo uma análise de velocidade específica do local, desde que justificada;

b) Direcionalidade:

- A aplicação da mesma velocidade de projeto em todos os azimutes é sempre segura;

- Esta abordagem faz parte de um método não direcional no qual se considera que a velocidade de vento mais alta atinge a estrutura em seu azimute mais crítico;
- No entanto, para análises de conforto e estados limites de serviço, métodos direcionais podem ser usados, desde que justificados;

c) Amortecimento:

- O amortecimento das torres altas pode ter um efeito significativo nas forças de projeto e nas acelerações induzidas pelo vento;

- O amortecimento geral do edifício, tipicamente considerado no comportamento de estruturas de edifícios altos, pode ser adotado como o seguinte (\% de crítico) (Tabela 2);

d) Critérios de conforto:

- As acelerações máximas permitidas são definidas com base nos estudos de percepção humana;

- Como as pessoas deitadas tendem a ser mais suscetíveis às acelerações do que pessoas sentadas ou em pé, os limites de aceleração são diferentes para escritórios e apartamentos/hotéis (Tabela 3);

Tabela 3 - Acelerações permitidas para período de recorrência de 10 anos

\begin{tabular}{|c|c|}
\hline Aceleração \\
horizontal \\
permitida para \\
\hline Tipo de \\
ocupação \\
$\begin{array}{c}\text { periodo de } \\
\text { recorrência } \\
\text { do vento }\end{array}$ \\
\hline Escritório & 20 a 25 milli-g \\
\hline Apartamento/Hotel & 15 a 18 milli-g \\
\hline
\end{tabular}




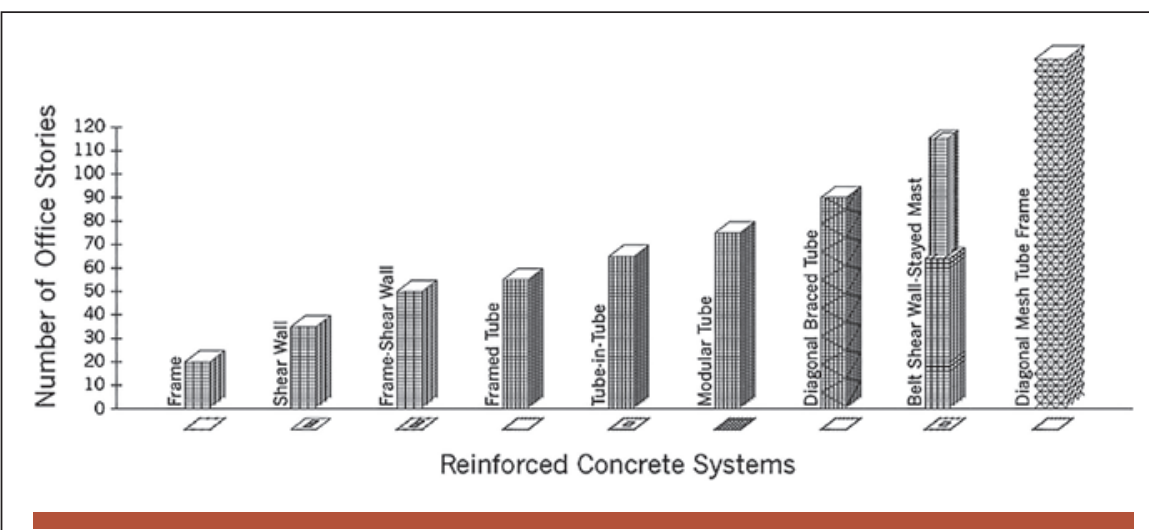

Figura 3

Sistemas em concreto armado em função da altura - extraído de Designing tall buildings. Fonte: Mark Sarkisian (2012)

e) Possibilidade de uso

de atenuadores:

- Para edificações com parâmetros acima dos limites estabelecidos no item anterior seria permitido o uso de atenuadores, que trabalham no sentido de impedir que os limites sejam atingidos;

f) Sistema de controle ativo:

- Seria permitido o uso de ate- nuadores de massa, como sistema de controle ativo;

- Esse tipo de sistema se vale de energia externa para controlar os efeitos de vibrações indesejáveis;

- Desta forma, o uso deste sistema só é permitido através de uma garantia de manutenção e exige a instalação de gerador elétrico, com capacidade para a operação do sistema;

g) Monitoramento de edifícios altos:

- Para edifícios com mais de $120 m$ de altura, seria obrigatória a instalação de monitoramento de sistema acoplado que faça a medição de velocidade de vento e aceleração em algum ponto da cobertura do edifício, sendo opcional em edifícios mais baixos;

- No caso de monitoramento de edifícios, seria permitido adotar o período de recorrência de 1 ano na definição do Vo para análise de conforto, uma vez que entendemos que a informação disponível gera segurança ao usuário que, desta forma, aumenta o seu nível de aceitabilidade;

h) Deformações em estado limite de serviço:

- De qualquer forma, ficaria explícito que ainda deve ser

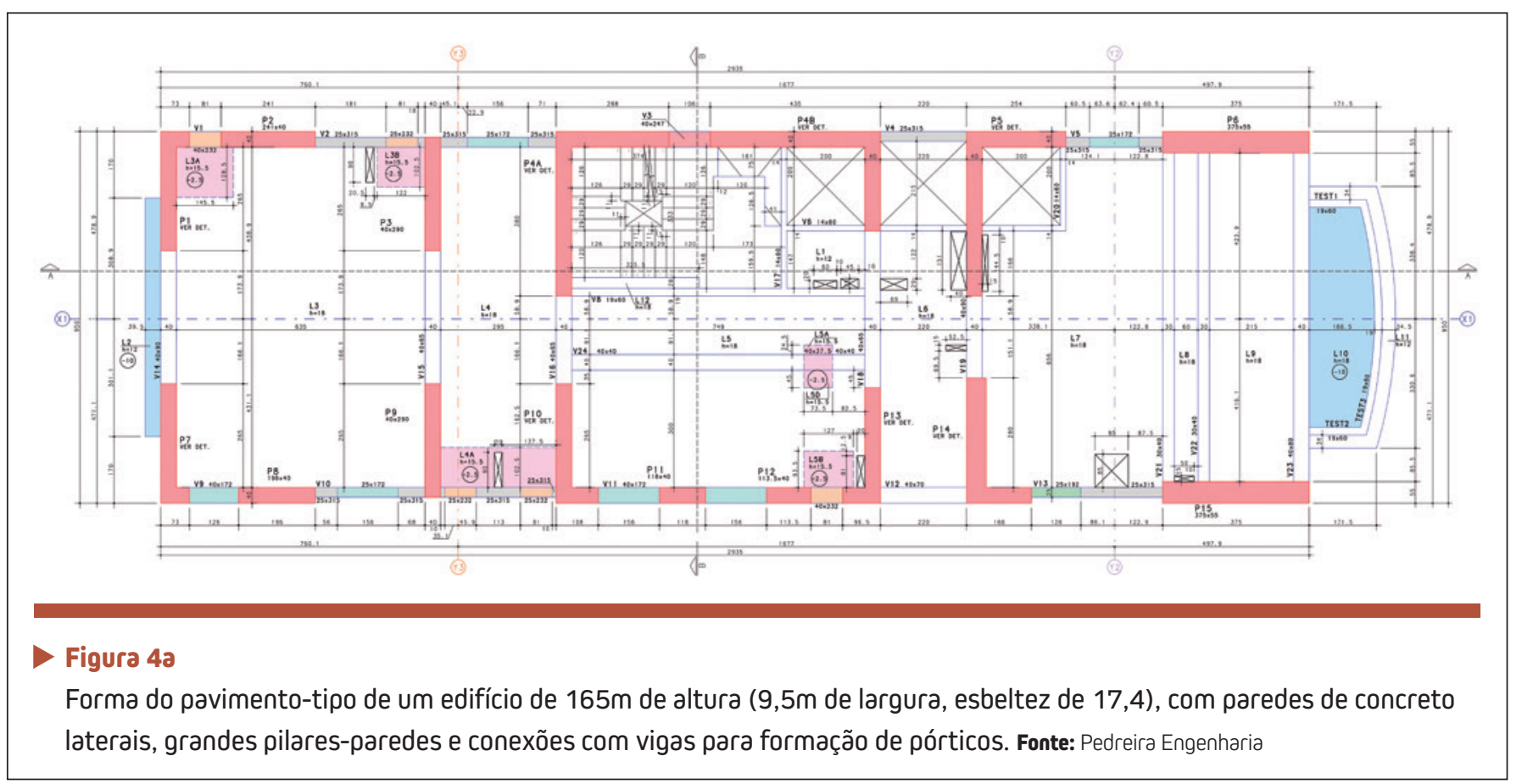




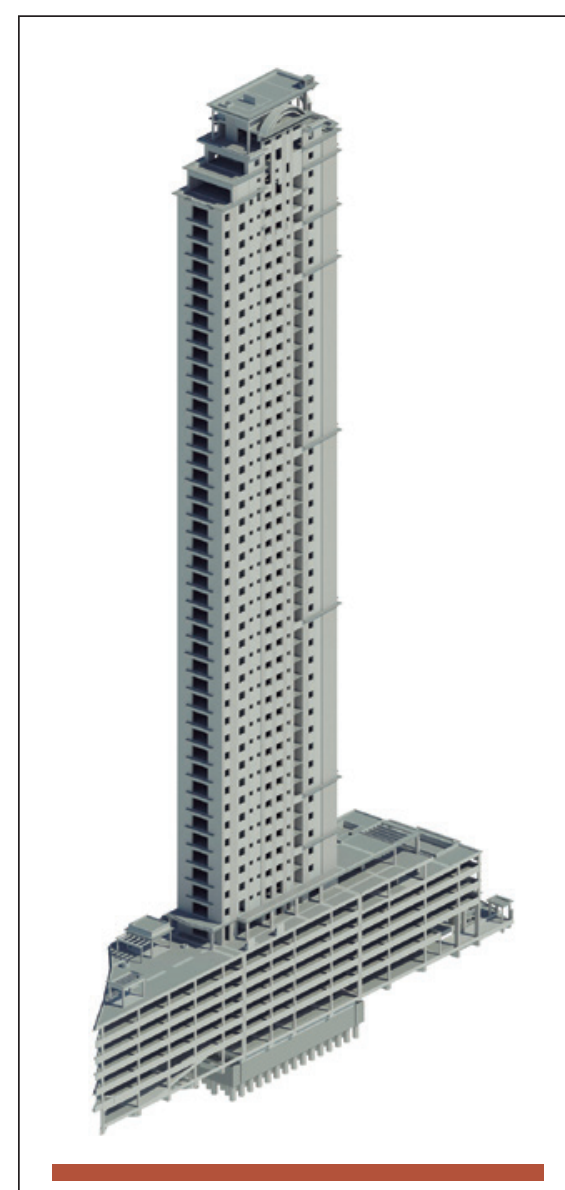

Figura 4b

Perspectiva do Edifício da Fig. $4 a$

Fonte: Pedreira Engenharia

feita, em ELS, a avaliação dos deslocamentos diferenciais entre pisos;

- Tanto para fins estruturais, quanto para a integridade de vedações e de elevadores;

- Apesar de não ser uma medida direta de conforto, pode conduzir a um desconforto visual.

\section{CONCEPÇÃO ESTRUTURAL}

Mark Sarkisian, em seu livro "Designing tall buildings", faz uma análise do Sistema estrutural adequado para os diversos números de pavimentos (Figura 3).

Apesar de muito altos, os prédios no Brasil ainda não estão na faixa dos "ultra-altos", ficando, por enquanto, no limite dos 80 pavimentos.

Ocorre, no entanto, que os prédios residenciais que estão sendo executados no Brasil, sobretudo os de Balneário Camboriú, não possuem arquitetura alinhada com esses sistemas estruturais, que trariam o melhor desempenho. Isso se deve pelo fato de existir uma predominância de 1 ou 2 apartamentos por andar, com fachada principal para o mar.

Assim, se faz necessária uma "tropicalização" dessas recomendações, buscando recursos para melhorar o desempenho da estrutura.
Temos visto (e usado) um misto entre estrutura articulada, com pórticos e grandes pilares-paredes, e, em alguns casos, tendo o incremento de paredes de concreto na periferia para conferir uma boa rigidez à estrutura, sem grande aumento de massa.

Entendemos que, para as arquiteturas com o que temos nos deparado, esta solução mista de Parede de Concreto e grandes pilares-paredes conectados por vigas, formando pórticos, é uma boa solução para esses prédios altos (Figuras $4 a$ e b).

Existem alguns artifícios que podem melhorar o desempenho estrutu-

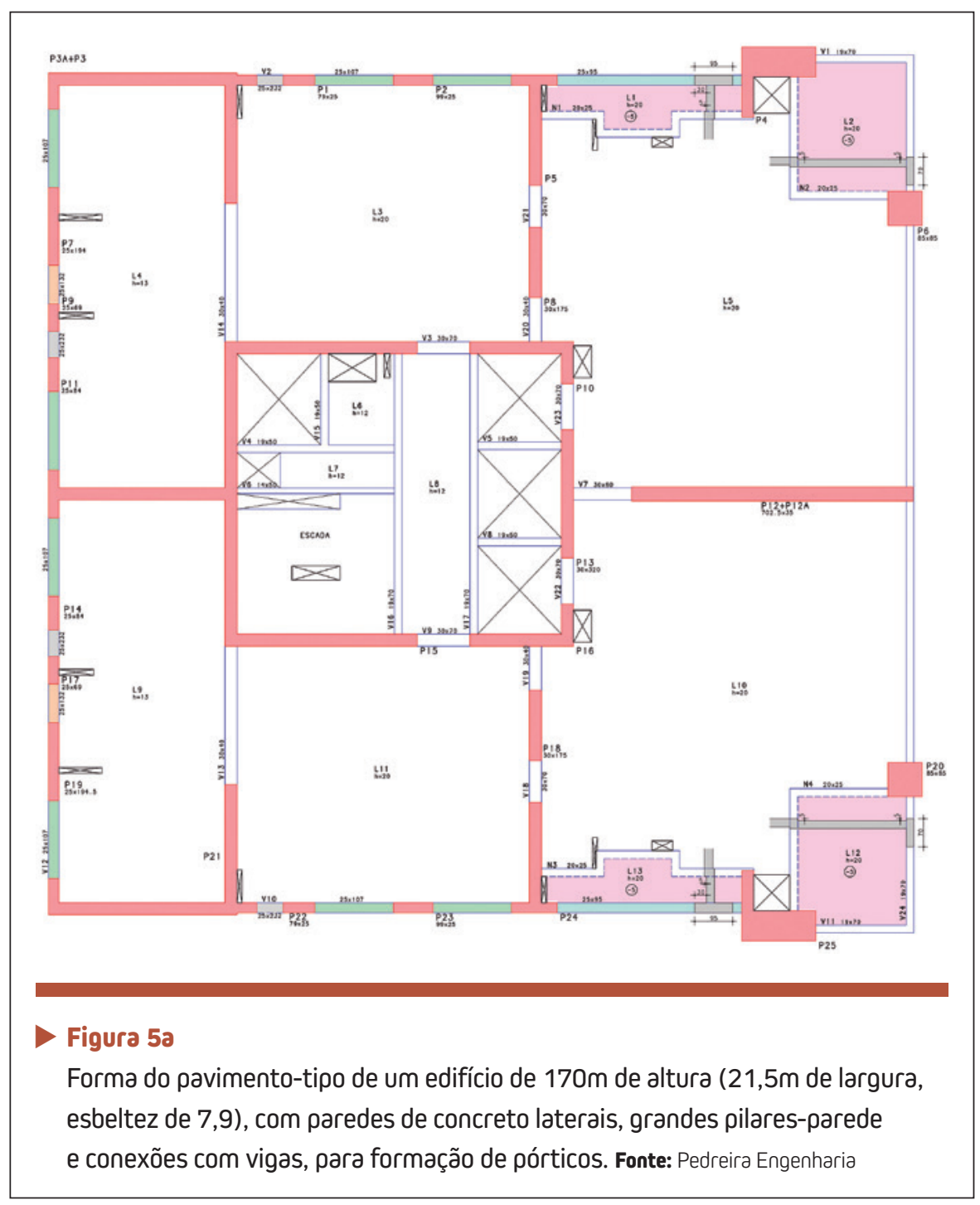


ral como, por exemplo, o uso de Outriggers (elementos de conexão rígidos entre núcleos e elementos estruturais mais afastados), que conferem um aumento de rigidez, ajudando, em alguns casos, de forma significativa na redução da aceleração e deformação global do edifício.

No exemplo das Figuras $5 a$ e b, seria criar em alguns andares intermediá-

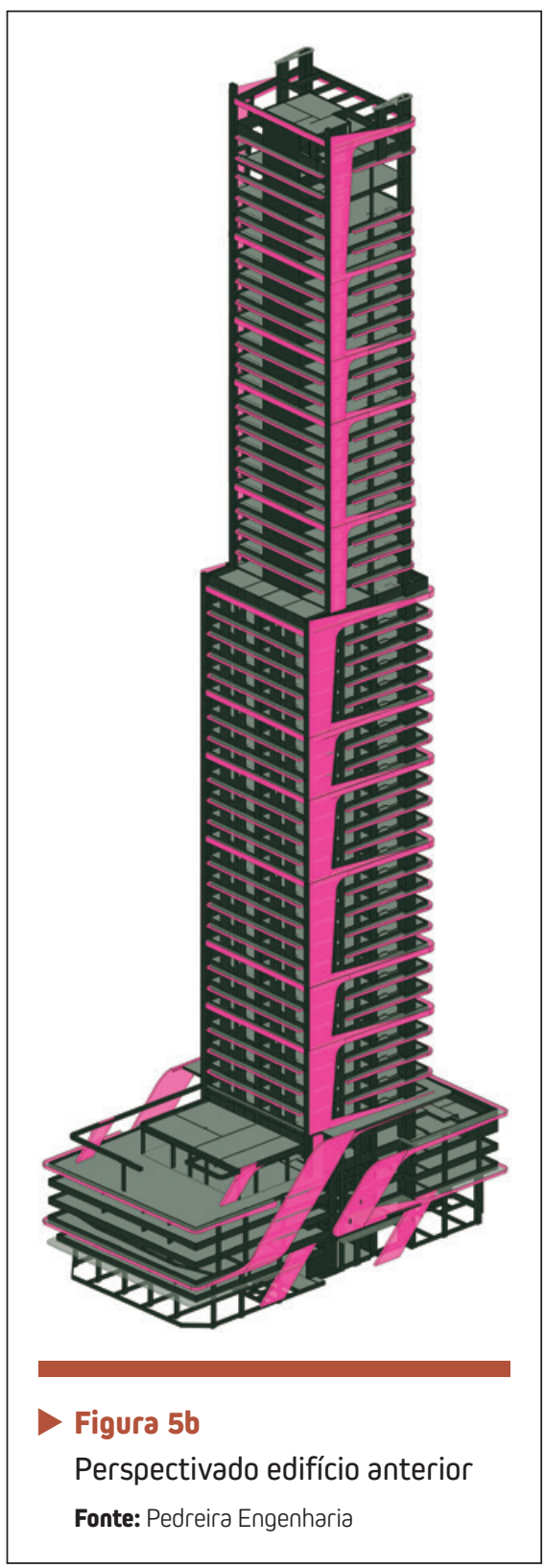

rios pavimentos técnicos, onde os pilares de periferia estivessem rigidamente ligados ao núcleo, conforme Figura 6.

\section{TÚNEL DO VENTO}

Uma das questões comuns no desenvolvimento de prédios mais altos é da necessidade da contratação de túnel de vento.

Têm sido discutidas pelo meio técnico as condições nas quais o túnel de vento é indispensável. Uma sugestão², nossa proposta para inclusão na revisão da norma (como anexo), seria:

a) Altura da edificação:
- Múltiplos andares: 152 m (a ASCE, Sociedade Americana de Engenheiros Civis, indica que o seu modelo de cálculo dinâmico para múltiplos andares não é mais válido a partir desta altura, sendo um indicativo de quando o túnel de vento é fundamental);

b) Altura em relação ao contexto:

- Se a edificação é suficientemente mais alta que as outras em seu entorno;

c) Forma:

- Forma irregular, que fuja dos "envelopes regulares";

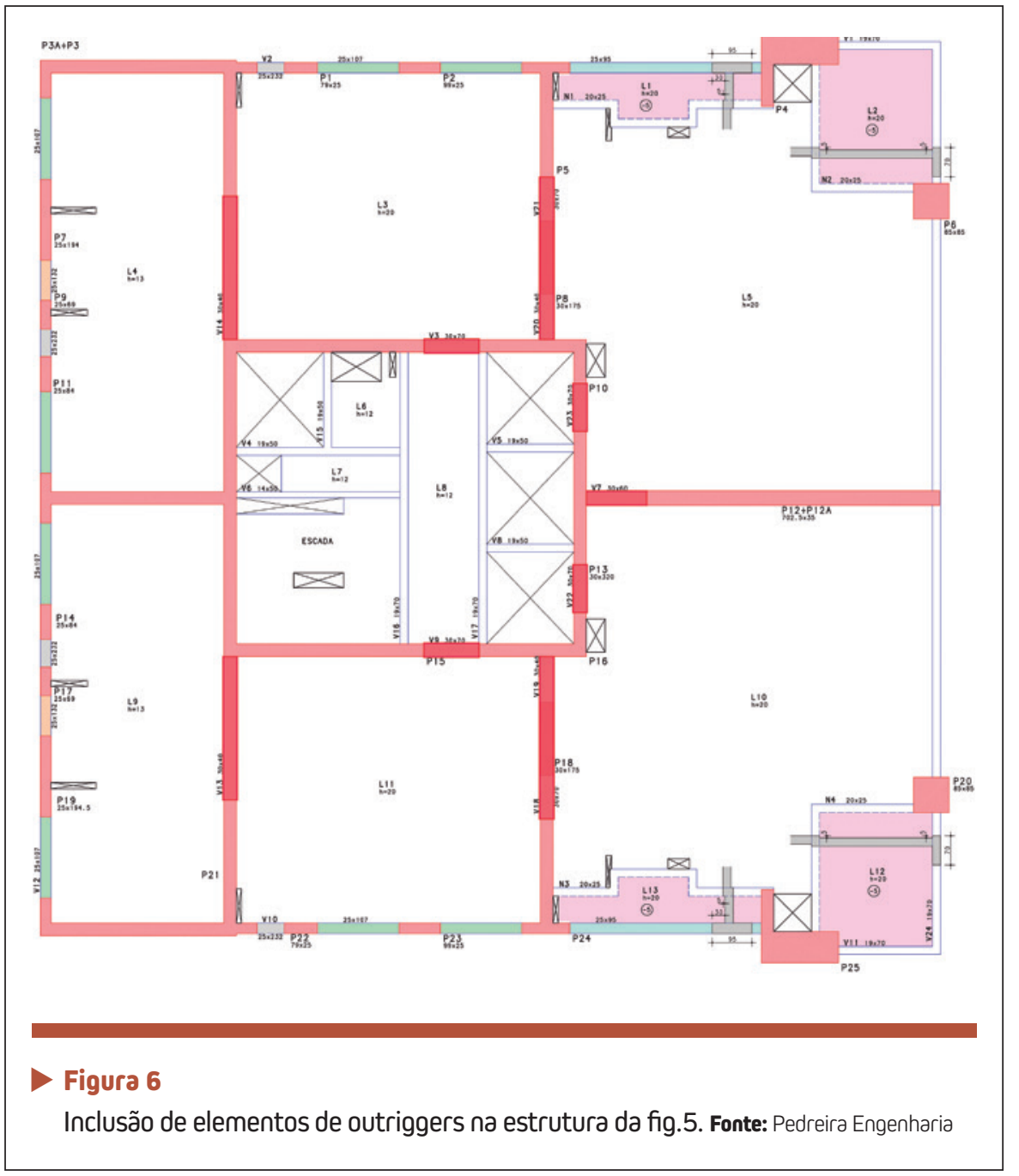

Baseado na contribuição de Johann A Ferrareto ao subcomitê da ABECE com base no CTBUH, ASCE, Eurocode AlJ-GEH-2004 para obrigatoriedade do ensalo de túnel DE VENTO. 
d) Estruturas flexíveis:

- Esbeltez: a ser definida com a realidade brasileira;

- Frequência natural: a ser definida uma frequência natural mais apropriada para a realidade brasileira;

- Estruturas com risco de instabilidade por galope, drapejamento ou susceptíveis à excitação por desprendimento de vórtices.

e) Estruturas com entornos complexos.

Nos prédios em que temos trabaIhado, solicitamos ensaio de túnel de vento em todos com altura maior que $120 \mathrm{~m}$, ou 40 pisos, mas sempre avaliando outras necessidades.

Para que o ensaio possa ser realizado, é fundamental que sejam fornecidos os seguintes dados, alinhando previamente com o laboratório as unidades e o sentido de leitura dos ângulos de incidência:

- Esquema de pavimentos e níveis;

- Parâmetros modais (períodos e frequências para cada modo de vibração da estrutura);

- Centro de massa e distribuição de massas por pavimento;

- Ponto de referência (não necessariamente o "centro de torsão");

- Formas modais para cada modo de vibração da estrutura.

Além disso, deve ser definido o tipo de ensaio a ser feito, dando preferência ao HFPI (High Frequency Pressure Integration), pelo qual são fornecidos, para diversas direções de vento, os carregamentos estáticos equivalentes que podem ser utilizados na Análise Estrutural para obter os esforços solicitantes em todas as peças estruturais. O outro ensaio, HFFB (High Frequency Force
Balance), permite uma análise mais direta do comportamento da estrutura aos esforços dinâmicos.

O Ensaio HFPI permite a integração das pressões com base nos resultados do túnel de vento e das características da estrutura. Estes dados, quando fornecidos de forma completa pelo túnel de vento (o que deve ser uma exigência), permite que seja feito uma otimização da estrutura pelo projetista com reanálise dos esforços com amplificação dinâmica através de modelos computacionais, sem a necessidade de novos ensaios. Isso é extremamente produtivo e desejável.

Os resultados do túnel de vento (obrigatoriamente acompanhados pela análise dinâmica) são de extrema importância para a avaliação dos critérios de conforto e para o dimensionamento dos elementos estruturais e da fundação.

O nosso entendimento é que o Laboratório do Túnel de vento deve nos fornecer:

- Cargas Equivalentes Acumuladas em cada direção;

- Cargas ao longo do edifício em cada direção;

- Cargas Estáticas Equivalentes (com amplificação dinâmica):

- Lembrando que as cargas estáticas equivalentes são aplicadas no ELU, mas obtidas com parâmetros modais no ELS;

- Atenção para unidades no sistema SI e ângulos de aplicação;

- Acelerações para TR $=10$ anos (para cada direção, no piso mais crítico, pelo menos).

Pode ser solicitado ainda:

- Pressões nas Fachadas;

- Conforto de Usuários em circulações confinadas;

- Conforto ambiental.

\section{CASOS ESPECIAIS}

No caso de edifícios altos, o vento não só é muito importante na questão de conforto, como pode ser fundamental no dimensionamento e na viabilidade da estrutura.

Infelizmente, a experiência tem mostrado que resultados de túnel de vento podem nos trazer surpresas, exigindo:

- Maior rigidez na estrutura;

- Maior consumo de armação no detalhamento;

- Necessidade de mudança de arquitetura.

\section{I Efeito de vizinhança}

Este é um assunto extremamente delicado, pois a vizinhança existente na fase de projeto certamente sofrerá mudanças ao longo da vida útil do edifício. E o próprio edifício que está sendo projetado pode implicar mudança de comportamento em um edifício próximo.

Desta forma, existem algumas questões para as quais ainda não temos a resposta, mas que deveriam ser discutidas no meio técnico de forma a não termos comprometimento do de-

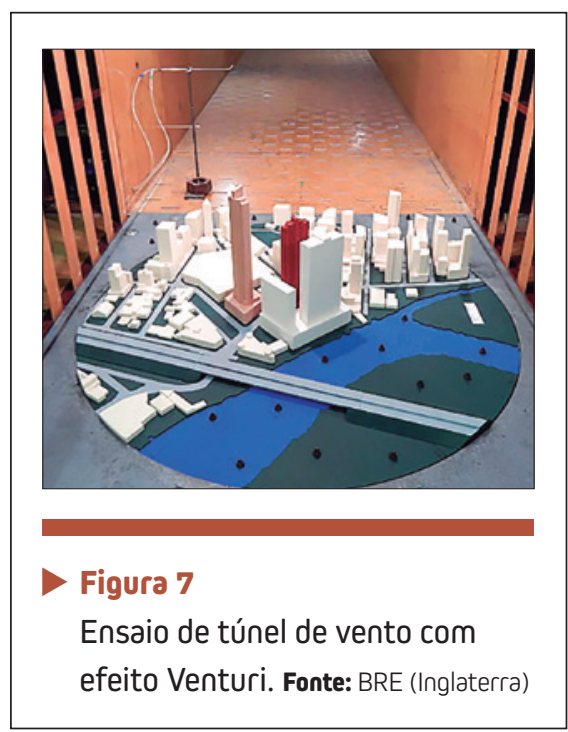


sempenho estrutural ao longo da vida útil do edifício:

- Como posso projetar uma estrutura para um período de vida útil de 50 anos se, ao longo desse período, outras construções podem alterar o esforço horizontal devido ao vento?

> Como prever o impacto que o edifício em fase de projeto pode gerar nos diversos edifícios existentes?

Questões difíceis de responder.

Temos um caso em que o túnel de vento mostrou claramente a formação de um efeito Venturi (quando a redução da área do fluxo do vento, numa zona de estreitamento, temos um aumento da velocidade do mesmo), aumentando o esforço em determinada direção devido à existência de 2 prédios altos próximos (Figura 7).

Se esses prédios não estivessem ali quando do túnel de vento, esses esforços maiores não seriam considerados.

\subsection{Desprendimento de Vórtices}

O fenômeno de desprendimento de vórtices (movimento forte e giratório do vento que surge quando este encontra um anteparo prismático, conforme observado na Figura 8) é algo pouco intuitivo e, por isso, extremamente perigoso.

Difícil acreditar que este fenômeno ocorra em estruturas com tanta massa quanto os nossos edifícios. Difícil, mas acreditem, pode ocorrer sim e o túnel de vento nos mostrar isso.

Tivemos uma estrutura que precisou alterar completamente a arquitetura em função deste fenômeno, visto na Figura 9, onde o vento na direção 20 provoca, através do desprendimento de vórtices, acelerações muito maiores que nas outras direções.

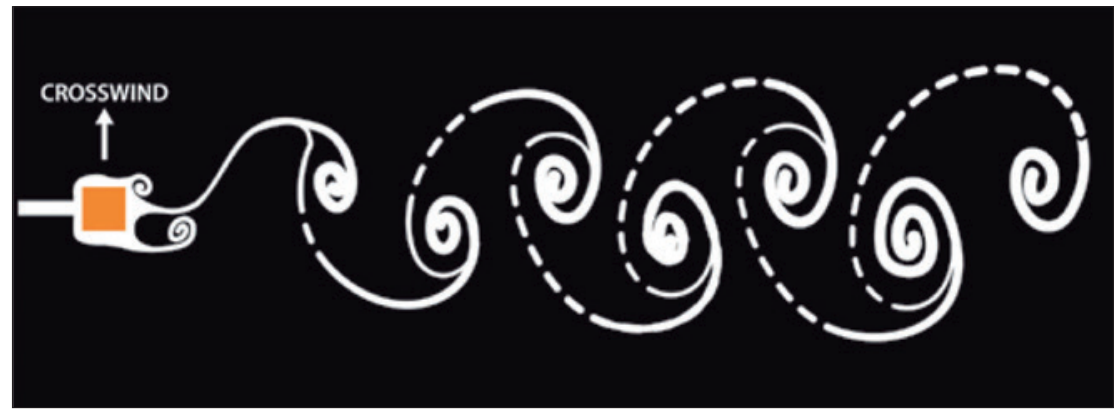

\section{Figura 8}

Esboço mostrando os padrões de desprendimento do vórtice, regularmente espaçados, que geram suas maiores forças perpendicularmente à direção do fluxo, causando vibrações no vento cruzado. Fonte: Structure Magazine (julho 2016)

Em alguns casos, este esforço pode ser absorvido por mais rigidez na estrutura (apesar de ficar antieconômico), mas, em outros, precisa ser alterada a condição aerodinâmica. Um exemplo deste

cuidado aerodinâmico é o emblemático Burj Khalifa, cujos ressaltos arquitetônicos são mais frutos desta análise aerodinâmica do que propriamente de um conceito estético (Figura 10).

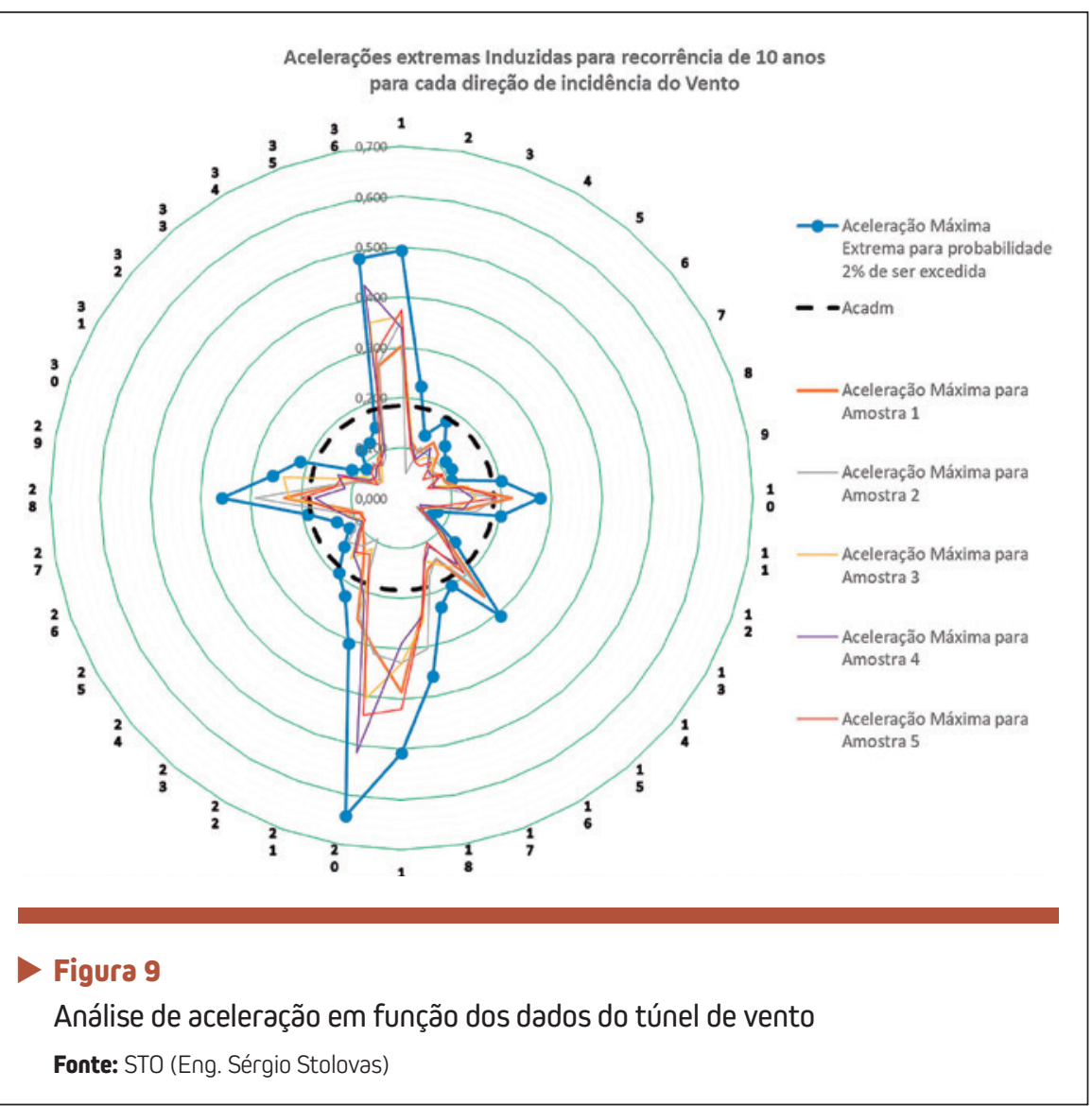




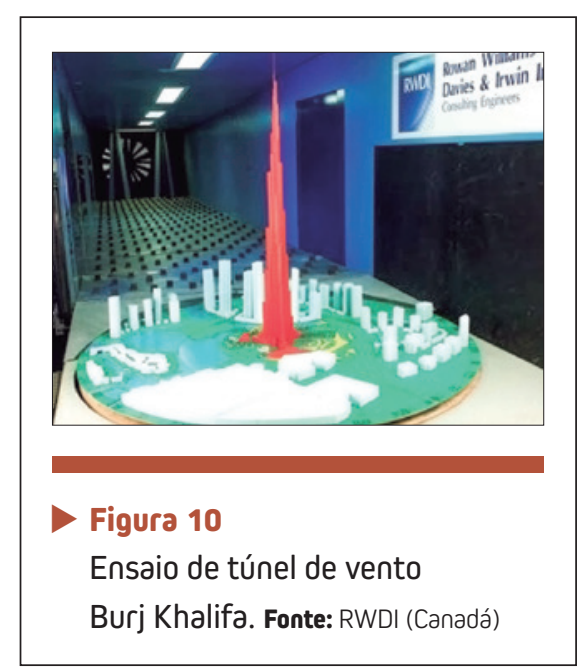

\subsection{Ressonância}

A questão da ressonância é administrável quando se pensa na estrutura. Afinal, mantendo a frequência natural da estrutura a uma distância segura da frequência de ressonância devido às oscilações horizontais, consegue-se estabelecer uma segurança estrutural.

Não se pode esquecer de que não é só a estrutura que é impactada pela altura. Outros componentes precisam ser analisados para que o desempenho do conjunto seja mantido, merecendo destaque as piscinas (que podem sofrer com a ressonância) e os caixilhos, que são muito demandados por algumas pressões de fachada.

\section{CONCLUSÕES E RECOMENDAÇÕES}

Este artigo não tem a pretensão de estabelecer parâmetros para uma análise criteriosa e detalhamento de edifícios altos. Nosso objetivo foi o de alertar para diversos pontos que precisam ser analisados, exaustivamente, para se ter um desempenho estrutural adequado.

Não foi possível abordar todos os pontos.

Nossas recomendações finais seriam:

a) Projetar prédios muito altos exige cuidados maiores do que os que estão nas nossas normas:

- Parâmetros que condicionam boas estruturas usuais podem não ser suficientes para estruturas de prédios muito altos;

b) O ELS (Estado Limite de Serviço, onde analisamos o Conforto) é fundamental para a concepção da estrutura e definição das seções geométricas e materiais;

c) O ELU (Estado Limite de Utilização, onde analisamos o limite para Ruptura) deve ser usado para verificar essas dimensões e definir as armações;

d) Túnel de vento + análise dinâmica são fundamentais e podem indicar problemas que não aparecem em modelos matemáticos;

e) Não recomendamos projetar um prédio muito alto de forma isolada (um único profissional):

- É muito importante uma equipe de grandes profissionais trabalhando em harmonia!

Não foi possível abordar outros temos, de muita relevância, tais como:

a) Interação solo $x$ estrutura:

- Fundamental em prédios muito altos, pois existem casos onde a não observação dos efeitos desta interação, resultaram em problemas de desempenho dessas Estruturas;

b) Execução dessas estruturas altas:

- Os Engenheiros profissionais de campo devem se atualizar para a execução deste tipo de estrutura, sendo fundamental ter em campo um engenheiro especializado na conferencia de forma, armação e lançamento de concreto;

c) Tecnologia de materiais (em especial o concreto);

d) Formas, que mereceriam um outro artigo.

\section{DREFERÊNCIAS BIBLIOGRÁFICAS}

[1] ABNT NBR 06118:2014 - Projeto de estruturas de concreto - Procedimento.

[2] ABNT NBR 06123:1988 - Forças devidas ao vento em edificações.

[3] Peviani, G. TCC Concepção estrutural e dimensionamento de pilares de um edifício de concreto armado pelas normas NB1 (196) e NBR 6118 (2003) - Uma visão de segurança, 2014.

[4] Vallis, M.B. Brazilian Extreme Wind Climate, 2019.

[5] Sarkisian, M. Designing tall buildings structure as architect, Routledge, 2012.

[6] Beck, A.T. Quantificação de incertezas em engenharia de estruturas, Ibracon, 2014.

[7] Riera, J.D. Sobre a definição do vento para projeto estrutural na ABNT 6123 (1989) e outras normas sul-americanas, Revista Sul-Americana de Engenharia Estrutural, 2016.

[8] Ferrareto, J.A. Conforto em edificações sob ação do vento, 2017. 